\title{
Life-threatening hypercalcaemia in association with Addisonian crisis
}

\author{
John Miell ${ }^{1}$, Alan McGregor ${ }^{1}$, Joan Butler ${ }^{2}$ and Richard Ross ${ }^{1}$ \\ Departments of ${ }^{1}$ Medicine and ${ }^{2}$ Clinical Biochemistry, King's College Hospital School of Medicine, \\ Bessemer Road, London SE5 9PJ, UK
}

\begin{abstract}
Summary: A 35 year old woman was admitted with acute radial artery occlusion necessitating two operations and thrombolytic therapy. Subsequently a diagnosis of primary hypothyroidism was made and she was commenced on thyroxine replacement therapy. Her condition, however, continued to deteriorate with the development of an Addisonian crisis heralded by, and complicated by, severe, life-threatening hypercalcaemia. This case highlights the importance of considering Addison's disease in any patient whose condition deteriorates after the introduction of thyroxine replacement, and illustrates the often forgotten association of hypercalcaemia and hypoadrenalism.
\end{abstract}

\section{Introduction}

Hypercalcaemia in association with hypoadrenalism was first described in $1932^{1}$ and although well recognized since, its true prevalence probably remains underestimated.

Life-threatening hypercalcaemia, however, is rare, and, in the published cases, has tended to occur in patients with associated parathyroid disease; either treated hypoparathyroidism ${ }^{2,3}$ or coexistent hyperparathyroidism. ${ }^{4} \mathrm{We}$ report a case of life-threatening hypercalcaemia heralding Addisonian crisis in a young female patient, who had recently been commenced on thyroxine replacement therapy following the diagnosis of primary hyperthyroidism.

\section{Case report}

A 35 year old Caucasian female presented with acute radial artery occlusion. She had been previously well, though had been investigated for infertility some 5 years previously. She gave a strong family history of myocardial infarction in youth, and her mother had undergone thyroidectomy for Graves' disease. Despite operative intervention on two occasions and subsequent thrombolytic therapy combined with systemic anticoagulation she developed gangrene of the left hand. Post-operative recovery was further complicated by the development of non-specific chest

Correspondence: J.P. Miell, B.M., M.R.C.P. Accepted: 18 March 1991 pain, repeated hypotensive episodes, nausea and vomiting. Investigation revealed the following results: anaemia (Hb $9.6 \mathrm{~g} / \mathrm{dl}$ ), macrocytosis $(107 \mathrm{fl})$ and eosinophilia $(0.3 \%)$, normal B12 (499 ng/l, normal range: $180-800 \mathrm{ng} / \mathrm{l})$ and serum folate $(2.4 \mu \mathrm{g} / \mathrm{l}$ : normal range $1.6-10 \mu \mathrm{g} / \mathrm{l})$, ans elevated ESR at $81 \mathrm{~mm} / \mathrm{h}$; moderately impaired renal function (creatinine $174 \mathrm{mmol} / \mathrm{l}$ ) and hyperphosphataemia $(2.23 \mathrm{mmol} / \mathrm{l})$; normal chest X-ray and lung scan, fatty liver infiltration on ultrasound; elevated thyroid stimulating hormone (TSH) $(61 \mathrm{mU} / \mathrm{l})$, strongly positive thyroid microsomal antibodies $(1: 102,400)$, and elevated prolactin $(2,200 \mathrm{mU} / \mathrm{l})$. A diagnosis of primary hypothyroidism was made and she was commenced on thyroxine $100 \mu \mathrm{g} /$ day. Over the next 25 days her condition continued to deteriorate with the development of hyponatraemia, hyperkalaemia and hypercalcaemia. Serial calcium measurements (corrected for albumin) are illustrated graphically in Figure 1.

At the time of her peak corrected calcium (3.92 mmol/l), a single $09.00 \mathrm{~h}$ cortisol measurement was $60 \mathrm{nmol} / \mathrm{l}$, and she was referred to the endocrine team. She was clearly unwell, hypotensive and dehydrated with pigmentation over her knuckles, elbows and in the recent operation scar. She was hyponatraemic $(122 \mathrm{mmol} / \mathrm{l})$ and hyperkalaemic $(5.3 \mathrm{mmol} / \mathrm{l})$. A short Synacthen test confirmed the diagnosis of Addison's disease; cortisols at 0,30 and 60 minutes were $<60,<60$ and $<60 \mathrm{nmol} / \mathrm{l}$, respectively, with a basal ACTH concentration of $698 \mathrm{ng} / \mathrm{l}$ (normal range: $10-80$ ). Adrenal antibodies on this, and two subsequent occasions, were negative. She was vigorously rehydrated and commenced on hydrocortisone 


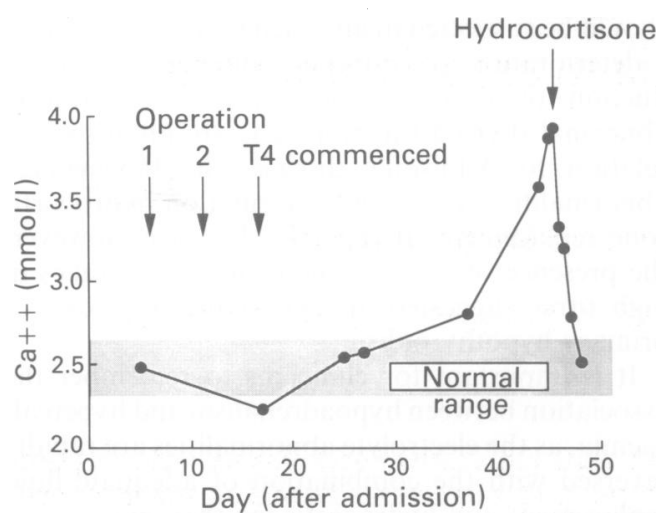

Figure 1 Variation in serum calcium concentrations (corrected for albumin) prior to and directly after commencement of hydrocortisone. The shaded area represents the normal range of our laboratory (T4 $=$ thyroxine).

$100 \mathrm{mg} 6$ hourly intramuscularly, resulting in a rapid symptomatic improvement and resolution of the electrolyte abnormalities within 48 hours. Levels of intact parathyroid hormone were undetectable prior to and 24 hours after the introduction of hydrocortisone; serial measurements of magnesium and vitamin $D$ were consistently within the lower end of the normal laboratory range. She subsequently made an uneventful recovery and at review 3 weeks later her prolactin had returned to normal $(370 \mathrm{mU} / \mathrm{l})$. Computerized tomography (CT) showed small adrenal glands.

No cause for her radial artery occlusion was established; her clotting screens were normal, estimations of protein $\mathrm{C}$, protein $\mathrm{S}$ and antithrombin 3 concentrations were within the normal range, anti-cardiolipin antibodies were negative, and echocardiography revealed no source of embolus.

\section{Discussion}

Our patient had primary hypothyroidism and Addison's disease heralded by hypercalcaemia. Despite the negative adrenal antibodies it is likely that the Addison's disease was autoimmune in origin as she had small adrenals on her CT scan and strongly positive thyroid antibodies. Adrenal antibodies are not always found in Type II polyglandular autoimmune disease.

Early reviews in $\operatorname{man}^{5-9}$ and adrenalectomized $\operatorname{dogs}^{5}$ suggest that the incidence of hypercalcaemia in hypoadrenalism is approximately equivalent to that of hyponatraemia, although there would appear to be no direct correlation between the two parameters in the same subjects.

The mechanisms involved in the development of hypercalcaemia in Addison's disease are not fully understood, but would appear to be independent of changes in parathyroid hormone and vitamin D concentrations. Indeed, the raised phosphate estimations and undetectable parathyroid hormone levels in our patient are against any abnormality in parathyroid hormone secretion. There are three remaining possible mechanisms: increased calcium absorption from the gut, increased calcium absorption from bone and decreased renal excretion of calcium.

Walser and colleagues ${ }^{5}$ studied the effects of adrenalectomy on mongrel dogs. Animals fed a calcium- and magnesium-free diet demonstrated the same incidence and degree of hypercalcaemia as those fed a normal diet, suggesting that increased calcium absorption from the gut would not appear to be an important factor in the development of hypercalcaemia.

Jowsey and Simons ${ }^{10}$ investigated the contribution of increased bone resorption of calcium, particularly with respect to the associated effects of thyroxine. Mongrel dogs were divided into three groups, each group undergoing either thyroidectomy, thyroparathyroidectomy or parathyroidectomy. Following the neck surgery, animals were subjected to adrenalectomy and were treated with prednisolone until post-operative recovery was complete. Parathyroidectomized animals showed precipitous increases in calcium levels, despite being maintained on a calcium- and magnesiumfree diet. Thyroidectomized animals, on the other hand, showed no significant increases in calcium until thyroxine replacement therapy was commenced when there was a rapid rise in calcium concentrations; a situation analogous to that of our patient. It was concluded that hypoadrenal hypercalcaemia was due to increases in calcium resorption from bone, mediated by thyroxine.

A third possible mechanism involves the reduction in glomerular filtration rate occurring as a result of hypovolaemia, which in turn results in an increase in proximal tubular reabsorption of sodium with concurrent calcium reabsorption. In a well studied case, a patient with idiopathic hypoparathyroidism treated with vitamin $\mathrm{D}$ and calcium supplements developed Addison's disease associated with severe hypercalcaemia. ${ }^{2}$ Serial assessments of urinary sodium and calcium excretion were made when the patient was both on and off cortisone treatment. Cortisone replacement resulted in calciuresis with increased creatinine clearance, whereas withdrawal of cortisone (due to recurrent hypocalcaemia) led to natriuresis without calciuresis. These results, taken in conjunction with the observation of hypercalciuria in Cushing's disease and the fact that fluid replacement alone cannot reverse the hypercalcaemia of Addison's disease, suggest that an adequate circulating level 
of corticosteroid is a prerequisite for the unimpaired excretion of calcium:

In summary, hypercalcaemia in Addison's disease is not uncommon, although life-threatening levels are rarely attained. In this case it seems highly likely that the hypercalcaemia was due to adrenal insufficiency as other causes of steroid responsive hypercalcaemia had been excluded by detailed investigation. The aetiology of hypoadrenal hypercalcaemia would appear to be multifactorial with alterations in the resorption of calcium from bone and its urinary excretion. In this case, it seems highly likely that the introduction of thyroxine therapy had the dual effect of unmasking Addison's disease and contributing to the associated hypercalcaemia. Indeed, Addison's disease

\section{References}

1. Loeb, R.F. Chemical changes in the blood in Addison's disease. Science 1932, 76: 420-421.

2. Walker, D.A. \& Davies, M. Addison's disease presenting as hypercalcaemic crisis in a patient with idiopathic hypoparathyroidism. Clin Endocrinol 1981, 14: 419-423.

3. Farrell, P.M., Rikkers, H. \& Moel, D. Cortisol-dihydrotachysterol antagonism in a patient with hypoparathyroidism and adrenal insufficiency: apparent inhibition of bone resorption. J Clin Endocrinol Metab 1976, 42: 953-957.

4. Downie, W.W., Gunn, A., Paterson, G.R. \& Howie, G.F.A. Hypercalcaemic crisis as a presentation of Addison's disease. Br Med J 1977, i: 145-146.

5. Walser, M., Robinson, B.H.B. \& Ducket, J.W. The hypercalcaemia of adrenal insufficiency. $J$ Clin Invest 1963, 42: 456-465. should be suspected in any such patient who shows a deterioration in symptoms following the introduction of thyroid replacement. Furthermore, abnormal thyroid function tests are often seen in relation to Addison's disease, the biochemical abnormalities returning to normal on hydrocortisone replacement therapy. In this case, however, the presence of thyroid microsomal antibodies in high titres suggested an underlying diagnosis of primary hypothyroidism.

It is important for clinicians to remember the association between hypoadrenalism and hypercalcaemia, as the electrolyte abnormalities are rapidly reversed with the combination of adequate fluid replacement and hydrocortisone therapy.

6. Helve, $\mathbf{O}$. A study of the metabolism in Addison's disease II. On the metabolism of lipids, nitrogen and minerals, and on the vitamin C household. Acta Med Scand 1947, 128: 1-7.

7. Leeksma, C.H.W., De Graeff, J. \& De Cock, J. Hypercalcaemia in adrenal insufficiency. Acta Med Scand 1957, 156: 455-462.

8. Pederson, K.O. Hypercalcaemia in Addison's disease. Acta Med Scand 1967, 181: 691-694.

9. Jørgensen, H. Hypercalcaemia in adrenocortical insufficiency. Acta Med Scand 1973, 193: 175-179.

10. Jowsey, J. \& Simons, G. Normocalcaemia in relation to cortisone secretion. Nature 1968, 217: 1277-1278. 


\title{
Erratum
}

"Life-threatening hypercalcaemia in association with Addisonian crisis". Postgraduate Medical Journal 1991 67: 770-772.

The authors for this paper should have read as follows: John Miell', Wassif Wassif', Alan McGregor ${ }^{1}$, Joan Butler ${ }^{2}$ and Richard Ross ${ }^{1}$. Dr Wassif's name was unfortunately omitted from the list of authors.

\section{ANNOUNCEMENT}

FUTURE DEVELOPMENTS IN OESTROGEN REPLACEMENT AND OTHER THERAPIES OF POSTMENOPAUSAL BONE DISEASE

\author{
An International Conference to be held at \\ The Gloucester Hotel, London, UK on 2nd/3rd December 1991
}

A panel of distinguished speakers both from industry and academia will be discussing the very latest development in this exciting field of research

\begin{tabular}{llll} 
& \multicolumn{3}{c}{ WHO SHOULD ATTEND } \\
$\star$ & Scientists involved in Pharmaceutical R\&D & $\star$ & Rheumatologists \\
$\star$ & Endocrinologists & $\star$ & Epidemiologists \\
$\star$ & Geriatricians & $\star$ & Orthopaedic Surgeons
\end{tabular}

\section{TOPICS TO BE DISCUSSED}

$\star \quad$ The menopause, oestrogen replacement (HRT) and osteoporosis

$\star \quad$ Underused indications of HRT

$\star \quad$ The effect of oestrogens and progestogens on the cardiovascular system

$\star \quad$ Presentations by industry involved on the current trends and potential of HRT

$\star \quad$ Evaluations by industry of delivery methods available - oral, transdermal (patch \& gel), implants

$\star \quad$ Panel Discussion: 'Which is the HRT of the Future?'

$\star \quad$ Methods of prevention and treatment of osteoporosis

$\star \quad$ HRT and osteoporosis - prevention, treatment and compliance

$\star \quad$ Other treatment options:

Calcium and Vitamin D, Fluoride, Calcitonin, Bisphosphonates

$\star \quad$ Assessing the effectiveness of anti-osteoporotic drugs

$\star \quad$ The regulatory issues involved in treatment

$\star \quad$ A look to the Future ...

$\star \quad$ 'Hands on' involvement in diagnosing osteoporosis - using a bone densitometer

Organised by CHARTERHOUSE CONFERENCE \& COMMUNICATIONS LTD in collaboration with The Department of Rheumatology St Bartholomew's Hospital, London, UK

For a full conference programme, please contact: MISS CAROLINE ELLIOTT, Events Administrator, Charterhouse Conference \& Communications Ltd, 35 Cloth Fair, London EC1A 7JQ. Tel: (+ 44) $0716062435 \quad$ Fax. (+44) 0716062351 